\title{
COMPARATIVE BINDING OF BEEF AND HUMAN INSULIN TO INSULIN ANTIBODIES PRODUCED IN MAN AND GUINEA PIGS *
}

\author{
By GEROLD M. GRODSKY ANd PETER H. FORSHAM \\ (From the Metabolic Unit for Research in Arthritis and Allied Diseases and the Department \\ of Medicine, University of California School of Medicine, San Francisco, Calif.)
}

(Submitted for publication December 6, 1960; accepted January 27, 1961)

Two methods $(1,2)$ for the immunochemical assay of circulating human insulin have been described recently. Both are based on the displacement of insulin- $\mathrm{I}^{131}$ from antibody by the addition of unlabeled insulin but differ in the conditions employed for the combination of insulin to antibody and for the subsequent separation of the bound from free insulin. Beef insulin was used as the reference standard by Grodsky and Forsham (1) because $a$ ) human insulin of sufficient purity to allow determination of its specific insulin content by biological assay was not available, and $b$ ) it was shown that human and beef insulins bind to guinea pig antibeef insulin antibody in a proportional relationship. Yalow and Berson (2) criticized the use of beef insulin as a standard, stating that human and beef insulins react disproportionately with guinea pig antiserum.

In other communications $(3,4)$, a 25 - to 100 fold difference between the affinity of human insulin and beef insulin for antibodies produced in the human against antibeef-pork insulin was reported.

The importance of these phenomena in the immunoassay of circulating insulin, as well as their effect on the metabolism of this hormone, has recently become apparent. On the basis of these considerations, we undertook to reinvestigate the quantitative relationship between beef and human insulin for binding to guinea pig and human antibody.

\section{MATERIALS AND METHODS}

Bovine crystalline insulin, lot no. T-2842, was obtained from Eli Lilly \& Co. Fisher human insulin ${ }^{1}$ was received in 1960 from the Connaught Labs., Toronto, Can-

* Supported by Grant A-3869 from the National Institute of Arthritis and Metabolic Diseases and by a grant from Eli Lilly \& Co.

${ }^{1} \mathrm{We}$ are greatly indebted to Dr. A. M. Fisher for supplies of this preparation. ada (assay in $1956=6.8 \mathrm{U}$ per $\mathrm{mg}$ based on a standard containing $22 \mathrm{U}$ per $\mathrm{mg}$ ). Individual extracts containing crude human insulin were prepared from human pancreas obtained at surgical biopsy (preparation A) or at autopsy (preparations B and C) by a modification (5) of the Jephcott procedure (6). An identical extract of bovine insulin was similarly prepared from fresh ox pancreas. Human antiserum was obtained from a subject with insulin-resistant diabetes at least 24 hours after any injection of beef-pork insulin.

Comparatice effect of changing concentration of becf or human insulin on the binding of beef insulin- $I^{131}$ to guinea pig insulin antibodics. The binding of beef insulin- $\mathrm{I}^{131}$ to antibodies against beef insulin produced in guinea pigs, and the subsequent precipitation of the bound insulin with sodium sulfite was described in a previous report (1). In some of the later studies precipitation was accomplished with sodium sulfate at $25^{\circ}$ in place of sodium sulfite at $4^{\circ} \mathrm{C}$. Sodium sulfate produced a more compact, easily centrifuged precipitate; however, results in either case were essentially the same. Each of the human insulin preparations was initially diluted with 5 per cent albumin so that after incubation and salt precipitation, the per cent insulin- $\mathrm{I}^{131}$ activity displaced into the supernatant was comparable with that produced by a beef insulin standard of $150 \mu \mathrm{U}$ of insulin per $\mathrm{ml}$. Thereafter, progressively increasing or decreasing concentrations of the diluted human insulin preparations were similarly treated, and the resulting per cent activity in such supernatant was plotted. If changing human insulin concentration causes a displacement of insulin- $\mathrm{I}^{131}$ from antibody proportional to that effected by changing beef insulin concentration, the curves obtained for the human and the beef insulins should coincide. This technique eliminates the necessity for using calculations of insulin content of the crude human preparations based on a biological assay.

The comparative affinity of human and beef insulin for human antibeef-pork insulin antibodies. Each preparation of human insulin was assayed by incubation with guinea pig antiserum and by comparison with a reference curve made after incubation of beef insulin with the same guinca pig antiserum. ${ }^{2}$ The human insulin preparations were then reassayed by incubation with human

2 Two different dilutions of the human insulin preparations were used for each determination. Determinations were repeated on 3 to 18 different days. 


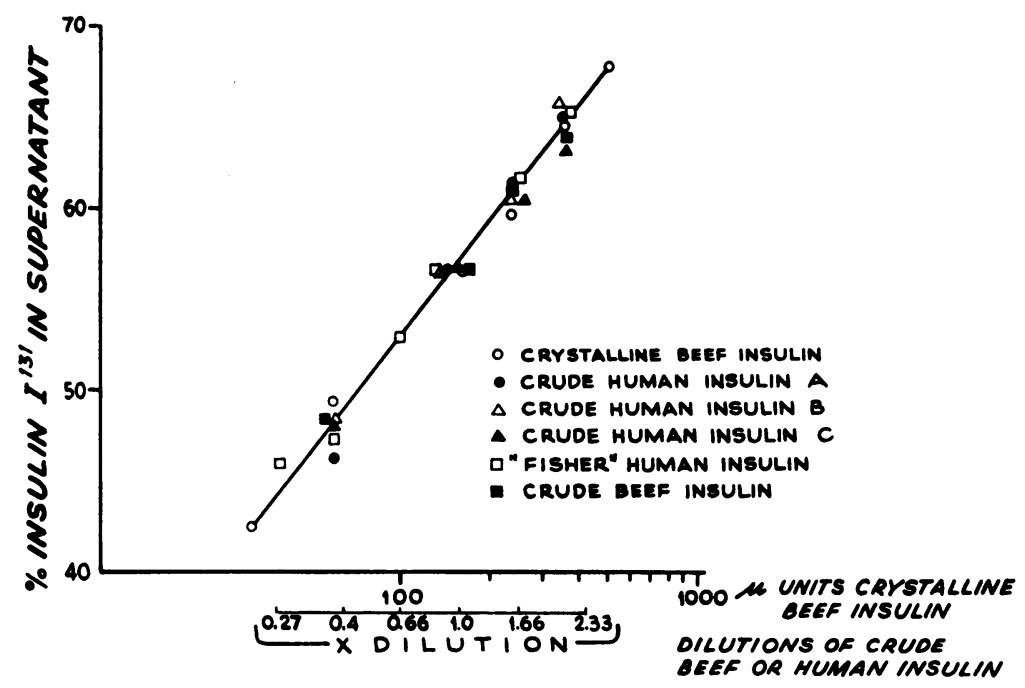

Fig. 1. Comparison of the effectiveness of proportional dilutions OF VARIOUS INSULIN PREPARATIONS IN DISPLACING BEEF INSULIN-I ${ }^{131}$ FROM GUINEA PIG ANTI-INSULIN SERUM.

antiserum and comparison with a reference curve made after incubation of beef insulin with human antiserum. If the affinity of human insulin for human antibody is poor, the assay of the human insulin in systems using human antisera would be much lower than the comparative assay against guinea pig antisera. In this study, too, a biological assay of the human preparations was not necessary.

\section{RESULTS}

For the range of insulin concentrations employed, the percentage of radioactivity in the supernatant after incubation was generally proportional to the log of the concentration of added unlabeled insulin. The supernatant activities after incubation of various dilutions of each of the human insulin preparations are plotted in Figure 1. The three crude human insulin preparations, the Fisher insulin, and the extract of beef pancreas produced points which, within the error of the method, coincided exactly with the reference curve produced by the crystalline beef insulin. The Fisher insulin, when assayed against guinea pig antibeef insulin antibody, contained $4.04 \pm 0.87 \mathrm{U}$ or $144 \pm 31 \mu \mathrm{g}$ of insulin per $\mathrm{mg}( \pm=2 \times \mathrm{SE})$. Results were unchanged when the incubations were carried out at $\mathrm{pH} 7.4$ instead of 8.6 or for periods of 4 days instead of 1 hour.

Results of assays using crystalline beef insulin as reference standards for the crude human insulin preparations $\mathrm{A}$ and $\mathrm{C}$, Fisher human insulin, and the crude beef insulin either were not sig- nificantly different or varied less than one-fold regardless of whether human antiserum or guinea pig antiserum was employed in the incubations (Figure 2). Although the assay of human insulin preparation $\mathrm{B}$ was significantly lower $(\mathrm{p}=<$ 0.001 ) when measured against human antisera than when measured against guinea pig antisera, the quantitative difference was less than threefold.

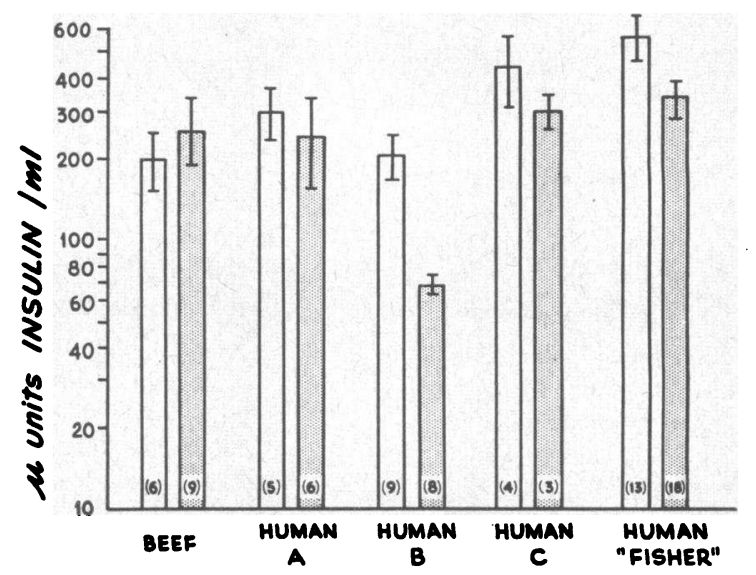

FIg. 2. IMMUNOCHEMICAL ASSAY OF BEEF AND HUMAN INSULIN IN SYSTEMS EMPLOYING INSULIN ANTIBODIES PRODUCED IN MAN AND GUINEA PIGS. Crystalline beef insulin was used for all reference curves. Figures in parentheses equal total number of determinations; $I=2 \times$ SE. Plain columns: unknowns and reference standards compared against guinea pig antiserum. Dotted columns : unknowns and reference standards compared against human antiserum. 


\section{DISCUSSION}

Our previous finding (1) that different concentrations of human and of beef insulin produce proportionate changes in the binding of insulin- $\mathrm{I}^{131}$ to guinea pig antibody has been confirmed with four different preparations of human insulin. Therefore, under the experimental conditions employed, changing concentrations of human insulin may be equated with an immunochemical system employing beef insulin standards.

According to Yalow and Berson (2), "beef insulin cannot be used as a standard for the assay of human insulin in the guinea pig antibody insulin system" and investigations employing beef standards are to be considered "invalid." The conditions of their experiments $(\mathrm{pH} \mathrm{7.4,} \mathrm{incuba-}$ tion time 4 days), however, were quite different from those used by Grodsky and Forsham (1) $(\mathrm{pH} 8.6$, incubation time 1 hour). Since both $\mathrm{pH}(7)$ and time of incubation (8) have a known effect on formation of insulin-antibody complexes, it was initially believed that differences in these or less obvious experimental conditions could have accounted for the different conclusions reached by the two investigations. In our experiments neither incubation at $\mathrm{pH} 7.4$ nor incubation for 4 days at $4^{\circ} \mathrm{C}$ altered the results. Although Yalow and Berson noted that "the relative degree to which human insulin and beef insulin react at different insulin concentrations varies several- fold," these conclusions are difficult to reconcile with their own data, as shown in Figure 3. If the ratio of bound to free insulin- $\mathrm{I}^{131}(\mathrm{~B} / \mathrm{F})$ obtained after incubation with the concentrations of Fisher human insulin estimated at $0.25,0.5,1.0$, 2.0, 2.5 and $3.0 \mathrm{~m} \mu \mathrm{g}$ per $\mathrm{ml}$ are read against the crystalline beef insulin curve, the resultant assays in "beef insulin equivalents" are $0.12,0.27,0.55$, $1.0,1.12$ and $1.35 \mathrm{~m} \mu \mathrm{g}$ per $\mathrm{ml}$, respectively. The proportionality (beef insulin equivalents/ assumed insulin content) varied only from 0.45 to $0.55 \mathrm{re}$ gardless of the point chosen along the curves for the calculations. Therefore, although the curves of Yalow and Berson for human and beef insulin diverge, they remain proportional to each other throughout the range where $\mathrm{B} / \mathrm{F}$ is sensitive to changing insulin concentration. Fisher human insulin was biologically assayed at $6.8 \mathrm{U}$ per $\mathrm{mg}$ in 1956, "but it was believed that the activity of the latter preparation might have decreased slightly ..." (2). These authors assigned a value of $6.0 \mathrm{U}$ or $282 \mu \mathrm{g}^{3}$ per $\mathrm{mg}$ to the Fisher insulin but did not report the calculations employed for estimating the insulin degradation over a 3 year interval. If one takes the actual insulin content of this preparation to be 0.45 to 0.55 of the estimated $6.0 \mathrm{U}$ and corrects for the difference in unit size between the Toronto standard ( $22 \mathrm{U}$ per $\mathrm{mg}$ ) and the Eli Lilly \& Co. standard ( 27 to $29 \mathrm{U}$ per

${ }^{3}$ This value representing $6 / 22 \times 1,000$ is more correctly $273 \mu \mathrm{g}$.

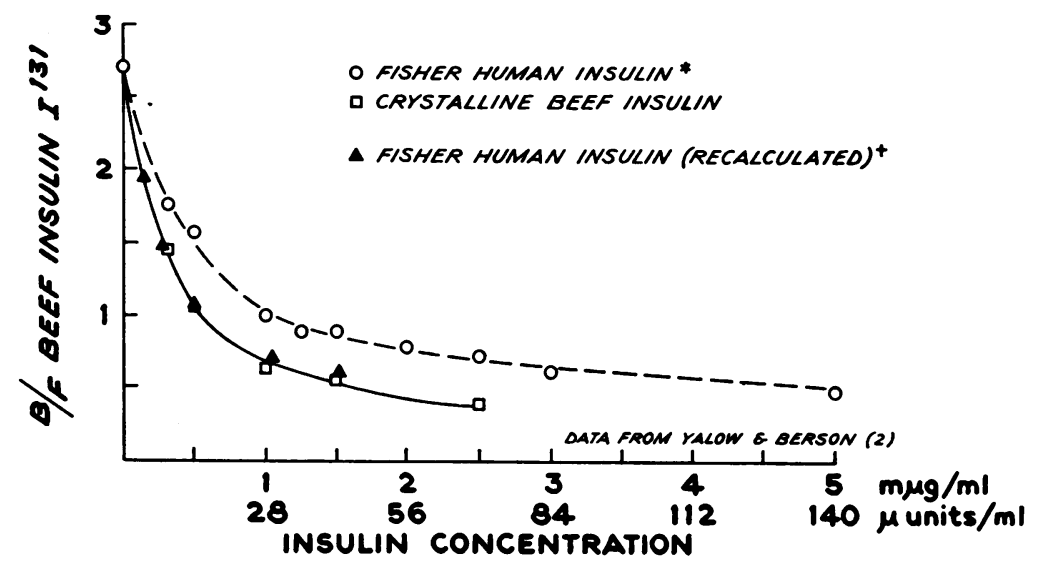

Fig. 3. COMPARISON OF THE EFFECTIVENESS OF VARIOUS CONCENTRATIONS of Fisher human insulin aNd CRYSTALline beEF INSUlin in REDUCiNG THE BOUND TO FREE (B/F) RATIO FOR BEEF INSULIN-I ${ }^{131}$. * Data plotted on basis of insulin content of Fisher preparation estimated as $282 \mu \mathrm{g}$ per mg (2). † Same data plotted on basis of insulin content of Fisher preparation assayed by Eli Lilly \& Co. as $146 \mu \mathrm{g}$ per $\mathrm{mg}$. 
$\mathrm{mg}$ ), a value of 3.44 to $4.21 \mathrm{U}$ or 122.5 to $150 \mu \mathrm{g}$ of insulin per $\mathrm{mg}$ for Fisher insulin is obtained. This value is in excellent agreement with our own finding of $4.04 \pm 0.87 \mathrm{U}$ or $144 \pm 31 \mu \mathrm{g}$ of insulin per $\mathrm{mg}$, based on immunoassay against a crystalline beef insulin standard. A portion of the Fisher insulin was sent to Eli Lilly \& Co. as a blind sample for biological assay. Its potency was reported to be $4.08 \pm 19.8$ per cent $U$ per $\mathrm{mg}^{4}(\mathrm{p}=0.05)$. If one replots the data reported by Yalow and Berson using this estimate of insulin content, the curves for human and beef insulin are almost superimposable (Figure 3). On the basis of our findings and the data of Yalow and Berson, it therefore appears that human and beef insulin effectively cross react in a proportional and nearly equivalent manner. [As stated previously, however, the exact evaluation of the quantitative relationship between human and beef insulin must await the availability of a crystalline insulin of sufficient purity to allow unequivocal determination of its insulin content by biological assay (1).] Since the Fisher preparation was used as a standard by Yalow and Berson for their assays of circulating insulin in human sera, their values perhaps should be reduced by approximately 50 per cent. Thus, normal human circulating insulin estimated at $27 \mu \mathrm{U}$ per ml (2) may be closer to $13 \mu \mathrm{U}$ per $\mathrm{ml}$.

In the report that the affinity of human insulin for human antibody was 25 to 100 times less than that of beef insulin, it was suggested that the nature of the three amino acids under the disulfide bridge in human insulin might be responsible for such differences in antigenicity (4). In contrast, our results showing the comparative agreement between the assay values for human insulin against beef insulin standards, when either guinea pig or human antisera were used, suggest that extracted human insulin binds almost as well to human antibeef-pork insulin antisera as does beef insulin. The finding by Nicol and Smith (9) that human insulin and pork insulin have an identical amino acid structure under the disulfide bridge strongly indicates that antigenic differences between extracted human insulin and insulin from this species (if they exist) do not occur at that site on the insulin molecule.

\footnotetext{
${ }^{4} \mathrm{We}$ are indebted to Mr. William Baum for the biological assay of this preparation.
}

SUMMARY

The comparative effect of changing the concentration of beef or human insulin on the binding of beef insulin- $\mathrm{I}^{131}$ to insulin antibodies produced in the guinea pig or man was reinvestigated, using a technique involving the separation of bound from free insulin by preferential salt precipitation.

Varying dilutions of four different preparations of crude human insulin produced changes in the binding of insulin- $\mathrm{I}^{131}$ to guinea pig antibody proportional to changes in concentration of crystalline beef insulin. Biological assay of the purest human insulin (Fisher insulin) was $4.08 \pm 19.8$ per cent $\mathrm{U}$ per mg. Immunological assay, using beef insulin as reference standard was $4.04 \mathrm{U}$ per $\mathrm{mg}, \mathrm{SE}=0.43$. It was concluded that extracted human and beef insulin cross react with guinea pig antibeef insulin in a proportional and nearly equivalent manner.

Agreement between the immunoassay values for human insulin against beef insulin standards when either guinea pig or human antisera were used was demonstrable, suggesting that extracted human insulin binds almost as well to human antibeef-pork insulin antisera as does beef insulin.

\section{REFERENCES}

1. Grodsky, G. M., and Forsham, P. H. An immunochemical assay of total extractable insulin in man. J. clin. Invest. 1960, 39, 1070.

2. Yalow, R. S., and Berson, S. A. Immunoassay of endogenous plasma insulin in man. J. clin. Invest. 1960, 39, 1157.

3. Berson, S. A., and Yalow, R. S. Recent studies on insulin-binding antibodies. Ann. N. Y. Acad. Sci. 1959, 82, 338.

4. Berson, S. A., and Yalow, R. S. Species-specificity of human anti-beef, pork insulin serum. J. clin. Invest. 1959, 38, 2017.

5. Grodsky, G. M., and Peng, C. T. Extractable insulin measured by immuno-chemical assay: Effect of tolbutamide. Proc. Soc. exp. Biol. (N. Y.) 1959, $101,100$.

6. Jephcott, C. M. Extraction of insulin and stability of various preparations. Trans. roy Soc. Can., Sect. V 1931, 25, 183.

7. Grodsky, G. M., Peng, C. T., and Forsham, P. H. Effect of modification of insulin on specific binding in insulin-resistant sera. Arch. Biochem. 1959, 81, 264.

8. Berson, S. A., and Yalow, R. S. Quantitative aspects of the reaction between insulin and insulinbinding antibody. J. clin. Invest. 1959, 38, 1996.

9. Nicol, D. S. H. W., and Smith, L. F. Amino-acid sequence of human insulin. Nature (Lond.) 1960, 187, 483. 